\title{
A COMPARATIVE STUDY ON ULTRASOUND-GUIDED PERIPHERAL INTRAVENOUS ACCESS VERSUS TRADITIONAL BLIND PERCUTANEOUS APPROACH IN PATIENTS WITH DIFFICULT INTRAVENOUS ACCESS
}

Zakiya Maryam ${ }^{1}$, Abraham Akkarapampil2 ${ }^{2}$ Sampathila Padmanabha Bhat ${ }^{3}$

${ }_{1}^{1}$ Post Graduate, Department of Anaesthesiology, Yenepoya Medical College.

2Professor, Department of Anaesthesiology, Yenepoya Medical College.

3 Professor and Head, Department of Anaesthesiology, Yenepoya Medical College.

\begin{tabular}{l}
\hline ABSTRACT \\
BACKGROUND \\
Obtaining quick and successful Intravenous (IV) access under acute settings of hospital management is done routinely with \\
ease in majority of patients. However, this task becomes challenging in patients with difficult intravenous access due to various \\
reasons needing multiple attempts with frustration to the clinician, pain and dissatisfaction to the patients.
\end{tabular}

\section{AIM}

To compare ultrasound-guided peripheral intravenous access with traditional blind percutaneous approach in patients with difficult intravenous access.

\section{SETTINGS AND DESIGN}

Prospective, cross-sectional, non-blinded, systematically allocated study done over a period of one month in patients with difficult IV access admitted in the MICU, SICU and POR (intensive care settings) of a tertiary care hospital.

\section{MATERIALS AND METHODS}

Difficult IV access was identified in those patients in which the available nurse had failed to obtain intravenous access after at least 3 blind percutaneous attempts; 32 patients included in the study were divided into 2 groups of sixteen each. The first group (US group) of patients was cannulated under ultrasound guidance. The second group (BP Group) was cannulated using the traditional blind percutaneous approach, where the veins were identified by palpation and visual inspection after a tourniquet placement. A maximum of 2 attempts were allowed before either procedure was declared unsuccessful. Patient characteristics, time from probe (US group) or tourniquet placement (BP group) to successful cannulation, number of attempts, complications and patient satisfaction were recorded.

\section{STATISTICAL ANALYSIS}

Chi-Square test was used to analyse the data obtained.

\section{RESULTS}

The US group showed quicker IV cannulation (190 seconds, SD 74.59 and $\mathrm{P}<0.001$ ) and more successful first attempts (62.5\%) with a higher patient satisfaction score (mean of 2.88, SD 1.025 and 'p' 0.049) when compared to the BP group, which took longer time (435.94 seconds) was less successful in the first attempt (31.2\%) and had lesser patient satisfaction $(2.0$, SD 1.36) with more complications.

\section{CONCLUSION}

When compared to the traditional blind percutaneous approach, intravenous cannulation by ultrasound guidance in patients with difficult intravenous access is quicker, more successful, requires fewer attempts and has a higher patient satisfaction with lesser complications.

\section{KEYWORDS}

Difficult IV Access, Ultrasonography, Blind Method, Attempt, Patient Satisfaction.

HOW TO CITE THIS ARTICLE: Maryam Z, Akkarapampil A, Bhat SP. A comparative study on ultrasound-guided peripheral intravenous access versus traditional blind percutaneous approach in patients with difficult intravenous access. J. Evolution Med. Dent. Sci. 2016;5(59):4074-4080, DOI: 10.14260/jemds/2016/933

Financial or Other, Competing Interest: None.

Submission 03-06-2016, Peer Review 08-07-2016,

Acceptance 13-07-2016, Published 23-07-2016.

Corresponding Author:

Zakiya Maryam,

\#13, $1^{\text {st }}$ Cross,

$5^{\text {th }}$ A-Block,

Koramangala,

Bangalore-560095.

E-mail: zakscarlet@yahoo.co.in

DOI: $10.14260 /$ jemds/2016/933

\section{INTRODUCTION}

Establishing intravenous (IV) cannulation is a basic and very important procedure in hospital practice. It is achieved routinely without much effort in most of the cases by location and palpation of the vein or by a blind transcutaneous approach. However, in patients with inaccessible peripheral veins, IV cannulation is difficult and challenging to the physician. The traditional approach is rendered difficult in obese patients, cases with anatomic variability of the veins, 
distorted veins, oedema and dehydration. The multiple blind attempts are painful and annoying to the patient.

Alternate methods include cannulation of the deep brachial vein, External Jugular Vein (EJV) or a central vein. These options have drawbacks such as limited skills of the clinician, invisible EJV, patient discomfort and associated complications like pneumothorax, deep vein thrombosis, etc.

Ultrasound (US) guidance offers a modality in facilitating precise location of the veins and enables a successful and rapid IV access in difficult cases. This method is shown to provide cannulation of veins that are neither visible nor palpable and obviates any need for a central line with its potential complications. ${ }^{[1,2]}$

Several prospective studies.[3,4,5] have shown increased success with ultrasound-guided cannulation. Studies comparing ultrasound-guided IV access with the traditional blind technique have found that ultrasound-guided IV access was more successful, required less time, reduced number of needle punctures and improved patient satisfaction. ${ }^{6,7,8]}$

Keyes and Coworkers.[9] evaluated an US-guided approach to percutaneous deep brachial vein or basilic vein cannulation in 101 Emergency Department (ED) patients with difficult IV access. They found that US-guided brachial and basilic vein cannulation was safe, rapid and had a high success rate of $91 \%$.

Also Bauman, Braude and Crandall, in a cohort study, compared US guidance versus standard technique of venous cannulation in 75 difficult vascular access patients by ED technicians. Rate of success, time to cannulation, number of punctures, doctor or nurse intervention, complications encountered and patient satisfaction were evaluated. Successful cannulation rates were similar for both traditional and ultrasound-guided approaches; however, US-guided approach was twice as faster, required lesser nurse or doctor intervention, was met with fewer complications and attempts with improved patient satisfaction as compared to the control group. ${ }^{[8]}$

Similarly, Brannam. ${ }^{[10]}$ performed a prospective, observational study in 321 difficult-to-stick patients. It was found that the ED nurses had a high success rate of $87 \%$ in obtaining peripheral vascular access with the use of ultrasound guidance after 45 minutes of training.

A questionnaire based survey of 146 patients receiving US-guided cannulation by Schoenfeld revealed that patient satisfaction was very high (9.2 of 10). [3]

A review study by Heinrichs J.[11] identified 4, 664 citations, assessed 403 full texts for eligibility and included 9 trials. The review concluded that ultrasonography may decrease peripheral intravenous cannulation attempts and procedure time in children in ED and operating room settings. A few outcomes reached statistical significance.

Seven papers which were found eligible were reviewed by Egan.[12] They found US guidance increased the likelihood of successful cannulation in difficult-access patients, just as the original studies had found (Odds ratio 2.42; $95 \%$ confidence interval 1.26-4.68).

Several other studies including recent meta-analyses and systematic reviews have shown that the use of bedside US decreases the number of needle insertion attempts, the number of potentially unnecessary central line placements, and increased patient satisfaction scores. This study aims to compare US-guided peripheral IV access with traditional blind approach in patients with difficult IV access.

\section{MATERIALS AND METHOD}

This was a prospective, cross-sectional, non-blinded, systematically allocated study done over a period of one month in patients with difficult to obtain IV access. Inclusion criterion for difficulty to obtain intravenous access was identified in those patients in whom any available nurse on duty had failed to obtain intravenous access after at least 3 blind percutaneous attempts. Paediatric and pregnant patients as well as those directly in need for a central line were excluded from the study.

Clearance for the study was obtained from the University Ethical Research Committee and informed consent was taken from the selected patients admitted in the Intensive Care Unit (MICU), Surgical Intensive Care Unit (SICU) and PostOperative Room (POR) of the Yenepoya Medical College Hospital.

Thirty two patients as per the inclusion/exclusion criteria were alternately allotted to two groups - US group and BP group. The US group patients had intravenous cannulation under ultrasound guidance, while the patients of BP group underwent cannulation by the blind method of inspection and palpation of veins with a tourniquet in place. Data collected was analysed using standard statistical methods and comparison between the two groups was studied.

The first group (US group) was cannulated under US guidance using GE Logiq P3 machine with a high frequency 11L transducer. The deep brachial vein was identified as a compressible vascular structure adjacent to the pulsatile and non-compressible deep brachial artery. The basilic vein was identified as a more superficial compressible vascular structure lateral to the deep brachial vessels.[9] While one assistant held the USG probe in place selected, the practitioner using the ultrasonographic image as a guide cannulated either vein with an 18G IV catheter.

The second group (BP Group) of patients was cannulated with an 18G IV cannula using the traditional blind percutaneous approach where the veins were identified by palpation and visual inspection after tourniquet placement.

A maximum of 2 attempts were allowed before either procedure was declared unsuccessful. Patient characteristics, time from probe placement (US group) and tourniquet placement (BP group) to successful cannulation, number of attempts, complications and patient satisfaction were recorded.

Complications including arterial puncture, haematoma, need for central line and any other significant complications as decided by treating physician were noted.

Successful cannulation was determined by the ability to infuse $10 \mathrm{~mL}$ of normal saline flush without infiltration.[13]

Patient satisfaction was measured using Likert scale from 0 to $4 .[14]$

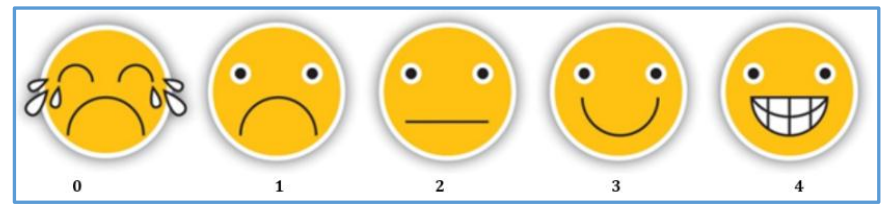


ETHICAL

Procedures followed were in accordance with the Ethical Standards of Yenepoya University Ethics Committee.

\section{RESULTS}

32 difficult to gain IV access patients were selected and divided into two groups of 16 each with 7 females and 9 males in each group as shown in Table 1 and Graph 1. Mean age of the participants in the US group was higher as shown in Table 2; however, there was no statistically significant difference with a $\mathrm{p}$ value of 0.288 .

Table 2 and Graph 2 show the comparison of the mean time taken for successful cannulation between the two groups. Mean time taken for successful cannulation in the US group was 190.06 seconds as compared to the BP group, where the mean time required was 435.94 seconds with a statistically significant difference with $p$ value of less than 0.001 .

The patient satisfaction scores compared between the two groups in Table 2 and Graph 3, showed that the participants of the US group had better mean satisfaction scores when compared to the BP group, which was significant with a $t$ value of 2.049 and $p$ value of 0.049 . Most patients in the US group had satisfaction scores of 3 and 4 when compared to the BP group patients who responded with scores of 1 and 2 as shown in Table 3 .

Analysis of the reasons for difficult IV access revealed the common causes to be obesity, oedema and deformities as shown in Table 4.

Table 5 shows $62.5 \%$ participants in the US group had successful cannulation in the first attempt when compared to $31.2 \%$ in the BP group.

Table 6 shows that seven patients failed to be cannulated in the BP group when compared to three in the US group.

$62.5 \%$ of the US group patients had no complications during the IV cannulation when compared to $43.8 \%$ in the BP group. The BP group had more incidence of complications when compared to US group; however, the incidence of haematoma formation was comparable between the groups as shown in Table 7.

Both the groups had high successful cannulation rate with requirement of central line placement in one patient in US group and 2 patients in the BP group as shown in Table 8.

\section{Statistical Analysis}

Standard Deviation (SD) in Group US $\left(\mathrm{S}_{1}{ }^{2}\right)=25.4$

$\mathrm{SD}$ in Group BP $\left(\mathrm{S}^{2}\right)=21.3$

Level of significance $(\alpha)=5 \%$

Power $(1-\beta)$ is $90 \%$

Sample size of 16 in each group is derived using the formula:

$$
n=2 \frac{S_{p}{ }^{2}\left(Z_{1-\alpha / 2} Z_{1-\beta}\right)^{2}}{\mu_{d}{ }^{2}}
$$

$$
\text { Where, } S p^{2}=\underline{S}_{1}{ }^{2}+\underline{S}_{2}^{2}
$$

CHI SQUARE TESTS FOR THE CATEGORICAL VARIABLES

\begin{tabular}{|c|c|c|c|c|c|}
\hline & \multicolumn{2}{|c|}{ GROUP } & \multirow{2}{*}{ Total } \\
\hline & & & US & BP & \\
\hline \multirow{4}{*}{ SEX } & \multirow[b]{2}{*}{$\begin{array}{c}\text { Female } \\
\text { (F) }\end{array}$} & Count & 7 & 7 & 14 \\
\hline & & $\begin{array}{c}\% \\
\text { within } \\
\text { Group }\end{array}$ & $43.8 \%$ & $43.8 \%$ & $43.8 \%$ \\
\hline & \multirow[b]{2}{*}{$\begin{array}{l}\text { Male } \\
\text { (M) }\end{array}$} & Count & 9 & 9 & 18 \\
\hline & & $\begin{array}{c}\% \\
\text { within } \\
\text { Group }\end{array}$ & $56.2 \%$ & $56.2 \%$ & $56.2 \%$ \\
\hline \multirow{2}{*}{\multicolumn{2}{|c|}{ Total }} & Count & 16 & 16 & 32 \\
\hline & & $\begin{array}{c}\text { \% } \\
\text { within } \\
\text { Group }\end{array}$ & $100.0 \%$ & $100.0 \%$ & $100.0 \%$ \\
\hline \multicolumn{6}{|c|}{ Table 1: Gender Distribution } \\
\hline
\end{tabular}

\begin{tabular}{|c|c|c|}
\hline \multicolumn{3}{|c|}{ Chi-Square Tests } \\
\hline & Value & Exact Sig. (2-sided) \\
\hline Pearson Chi-Square & .000 & 1.000 \\
\hline No. of Valid Cases & 32 & \\
\hline \multicolumn{2}{|c|}{ b. Computed only for a 2x2 table } \\
\hline
\end{tabular}

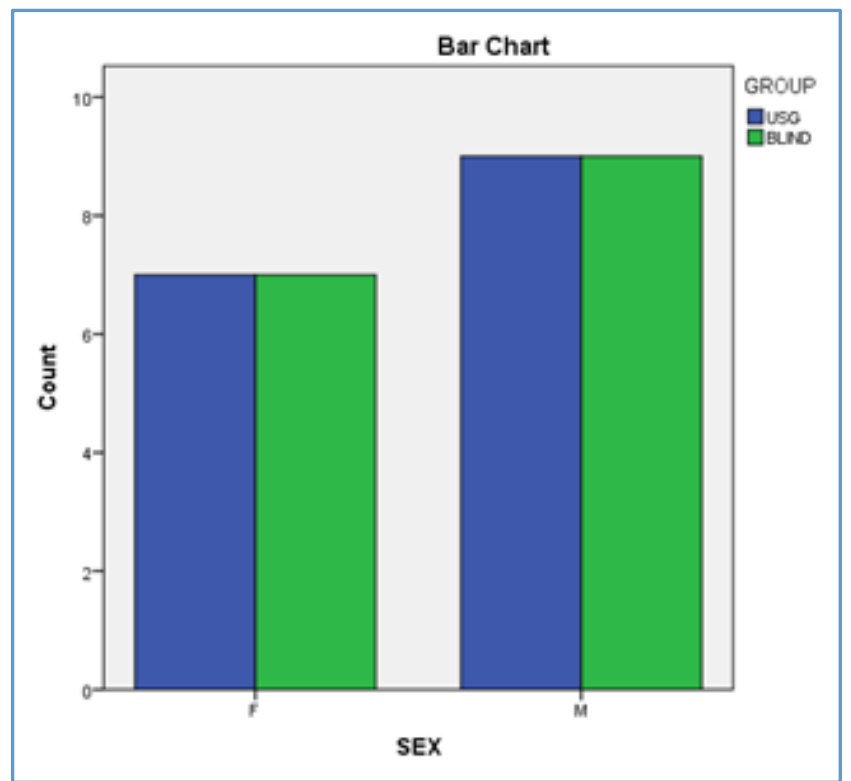

Graph 1: Gender Distribution

INDEPENDENT STUDENT'S T TEST FOR THE TIME AND AGE COMPARISONS WITH SATISFACTION SCORE

\begin{tabular}{|c|c|c|}
\hline \multicolumn{3}{|c|}{ Chi-Square Tests } \\
\hline & Value & Exact Sig. (2-sided) \\
\hline Pearson Chi-Square & .368 & 1.000 \\
\hline No. of Valid Cases & 32 & \\
\hline \multicolumn{3}{|c|}{ b. Computed only for a 2x2 table } \\
\hline
\end{tabular}




\begin{tabular}{|c|c|c|c|c|c|c|c|}
\hline & Group & $\mathbf{N}$ & Mean & Std. Deviation & $\mathbf{T}$ & Df & P value \\
\hline \multirow{2}{*}{ Age } & US & 16 & 54.13 & 12.285 & \multirow{2}{*}{1.081} & \multirow{2}{*}{30} & \multirow{2}{*}{0.288} \\
\hline & BP & 16 & 48.94 & 14.753 & & & \\
\hline \multirow{2}{*}{ Time (SEC) } & US & 16 & 190.06 & 74.598 & \multirow{2}{*}{-6.142} & \multirow{2}{*}{30} & \multirow{2}{*}{$<0.001$} \\
\hline & $\mathrm{BP}$ & 16 & 435.94 & 141.695 & & & \\
\hline \multirow{2}{*}{ Satisfaction } & US & 16 & 2.88 & 1.025 & \multirow{2}{*}{2.049} & \multirow{2}{*}{30} & \multirow{2}{*}{0.049} \\
\hline & $\mathrm{BP}$ & 16 & 2 & 1.366 & & & \\
\hline
\end{tabular}

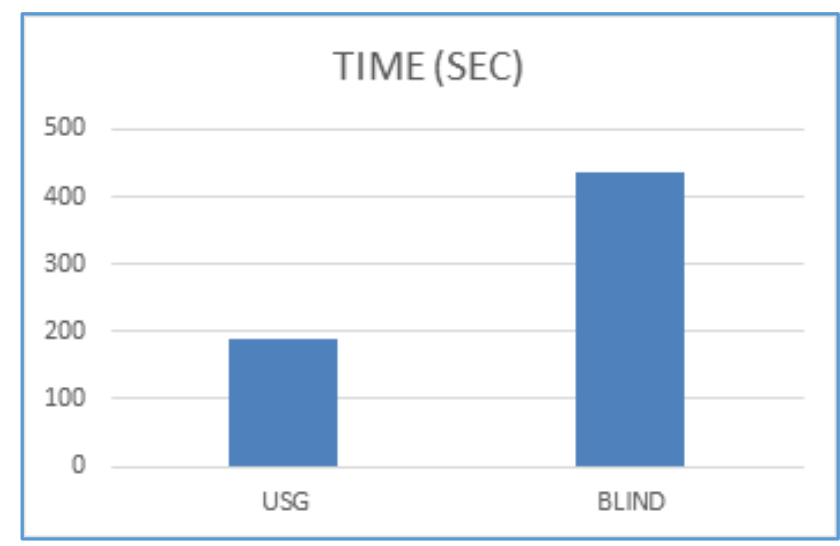

Graph 2: Average Time Taken for Successful Cannulation (In Seconds)

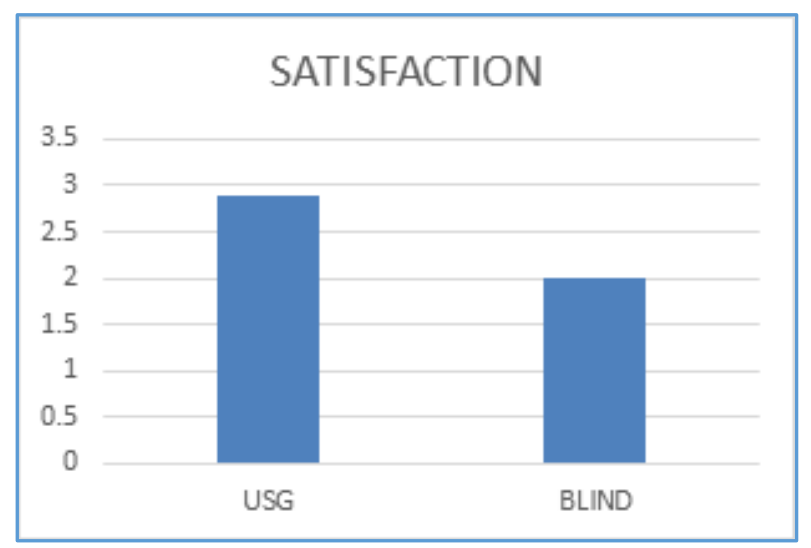

Graph 3: Average Patient Satisfaction Scores among the Two Groups

\begin{tabular}{|c|c|c|c|c|c|}
\hline & & & & & \\
\hline & & & US & BP & Total \\
\hline & 0 & Count & 0 & 2 & 2 \\
\hline & 0 & $\%$ within Group & $0.0 \%$ & $12.5 \%$ & $6.2 \%$ \\
\hline & & Count & 2 & 5 & 7 \\
\hline & 1 & \% within Group & $12.5 \%$ & $31.2 \%$ & $21.9 \%$ \\
\hline Cuticfortion & 2 & Count & 3 & 3 & 6 \\
\hline satıstaction & 2 & $\%$ within Group & $18.8 \%$ & $18.8 \%$ & $18.8 \%$ \\
\hline & & Count & 6 & 3 & 9 \\
\hline & 3 & \% within Group & $37.5 \%$ & $18.8 \%$ & $28.1 \%$ \\
\hline & & Count & 5 & 3 & 8 \\
\hline & 4 & $\%$ within Group & $31.2 \%$ & $18.8 \%$ & $25.0 \%$ \\
\hline & & Count & 16 & 16 & 32 \\
\hline Tota & & $\%$ within Group & $100.0 \%$ & $100.0 \%$ & $100.0 \%$ \\
\hline
\end{tabular}

\begin{tabular}{|c|c|c|}
\hline \multicolumn{3}{|c|}{ Chi-Square Tests } \\
\hline & Value & Exact Sig. (2-sided) \\
\hline Fisher's Exact Test & 4.388 & .374 \\
\hline No. of Valid Cases & 32 & \\
\hline
\end{tabular}

\begin{tabular}{|c|c|c|c|c|c|}
\hline & & & \multicolumn{2}{|c|}{ Group } & \multirow{2}{*}{ Total } \\
\hline & & & US & BP & \\
\hline \multirow{10}{*}{ REASON } & \multirow{2}{*}{ Obesity } & Count & 6 & 4 & 10 \\
\hline & & $\%$ within Group & $37.5 \%$ & $25.0 \%$ & $31.2 \%$ \\
\hline & \multirow{2}{*}{ Oedema } & Count & 3 & 4 & 7 \\
\hline & & \% within Group & $18.8 \%$ & $25.0 \%$ & $21.9 \%$ \\
\hline & \multirow{2}{*}{ Hypovolemia } & Count & 3 & 4 & 7 \\
\hline & & $\%$ within Group & $18.8 \%$ & $25.0 \%$ & $21.9 \%$ \\
\hline & \multirow{2}{*}{ Thrombosed veins } & Count & 1 & 1 & 2 \\
\hline & & $\%$ within Group & $6.2 \%$ & $6.2 \%$ & $6.2 \%$ \\
\hline & \multirow{2}{*}{ Deformity } & Count & 2 & 2 & 4 \\
\hline & & $\%$ within Group & $12.5 \%$ & $12.5 \%$ & $12.5 \%$ \\
\hline
\end{tabular}




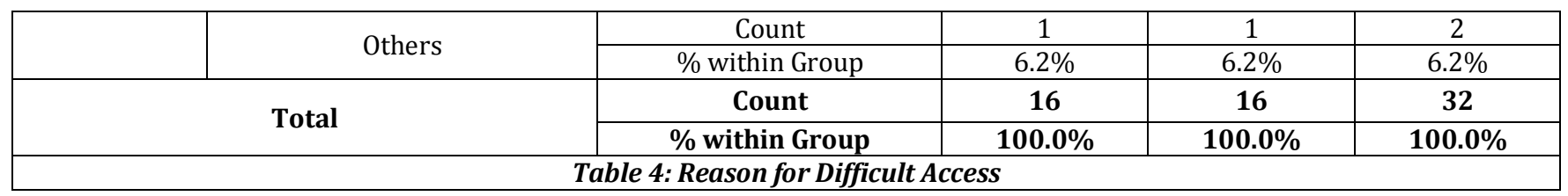

\begin{tabular}{|c|c|c|c|c|c|}
\hline & & & \multicolumn{2}{|c|}{ Group } & \multirow{2}{*}{ Total } \\
\hline & & & US & BP & \\
\hline \multirow{4}{*}{ ATTEMPTS } & \multirow{2}{*}{1} & Count & 10 & 5 & 15 \\
\hline & & \% within Group & $62.5 \%$ & $31.2 \%$ & $46.9 \%$ \\
\hline & \multirow{2}{*}{2} & Count & 6 & 11 & 17 \\
\hline & & \% within Group & $37.5 \%$ & $68.8 \%$ & $53.1 \%$ \\
\hline \multirow{2}{*}{\multicolumn{2}{|c|}{ Total }} & Count & 16 & 16 & 32 \\
\hline & & \% within Group & $100.0 \%$ & $100.0 \%$ & $100.0 \%$ \\
\hline \multicolumn{6}{|c|}{ Table 5: Attempts Taken for Successful Cannulation } \\
\hline
\end{tabular}

\begin{tabular}{|c|c|c|}
\hline \multicolumn{3}{|c|}{ Chi-Square Tests } \\
\hline & Value & Exact Sig. (2-sided) \\
\hline Pearson Chi-Square & 3.137 & .156 \\
\hline No. of Valid Cases & 32 & \\
\hline \multicolumn{2}{|c|}{ b. Computed only for a 2x2 table } \\
\hline
\end{tabular}

\begin{tabular}{|c|c|c|c|c|c|}
\hline & & & \multicolumn{2}{|c|}{ Group } & \multirow{2}{*}{ Total } \\
\hline & & & US & BP & \\
\hline \multirow{4}{*}{ SUCCESSFUL } & \multirow{2}{*}{ No } & Count & 3 & 7 & 10 \\
\hline & & \% within Group & $18.8 \%$ & $43.8 \%$ & $31.2 \%$ \\
\hline & \multirow{2}{*}{ Yes } & Count & 13 & 9 & 22 \\
\hline & & \% within Group & $81.2 \%$ & $56.2 \%$ & $68.8 \%$ \\
\hline \multirow{2}{*}{\multicolumn{2}{|c|}{ Total }} & Count & 16 & 16 & 32 \\
\hline & & \% within Group & $100.0 \%$ & $100.0 \%$ & $100.0 \%$ \\
\hline
\end{tabular}

\begin{tabular}{|c|c|c|}
\hline \multicolumn{3}{|c|}{ Chi-Square Tests } \\
\hline & Value & Exact Sig. (2-sided) \\
\hline Pearson Chi-Square & 2.327 & .252 \\
\hline No. of Valid Cases & 32 & \\
\hline
\end{tabular}

\begin{tabular}{|c|c|c|c|c|c|}
\hline & & & \multicolumn{2}{|c|}{ Group } & \multirow{2}{*}{ Total } \\
\hline & & & US & BP & \\
\hline \multirow{6}{*}{ COMPLICATIONS } & \multirow{2}{*}{ NONE } & Count & 10 & 7 & 17 \\
\hline & & $\%$ within Group & $62.5 \%$ & $43.8 \%$ & $53.1 \%$ \\
\hline & \multirow{2}{*}{ ARTERIAL PUNCTURE } & Count & 1 & 2 & 3 \\
\hline & & $\%$ within Group & $6.2 \%$ & $12.5 \%$ & $9.4 \%$ \\
\hline & \multirow{2}{*}{ HАEMATOMA } & Count & 5 & 7 & 12 \\
\hline & & $\%$ within Group & $31.2 \%$ & $43.8 \%$ & $37.5 \%$ \\
\hline \multirow{2}{*}{\multicolumn{2}{|c|}{ Total }} & Count & 16 & 16 & 32 \\
\hline & & \% within Group & $100.0 \%$ & $100.0 \%$ & $100.0 \%$ \\
\hline
\end{tabular}

\begin{tabular}{|c|c|c|}
\hline \multicolumn{3}{|c|}{ Chi-Square Tests } \\
\hline & Value & Exact Sig. (2-sided) \\
\hline Fisher's Exact Test & 1.277 & .584 \\
\hline N of Valid Cases & 32 & \\
\hline
\end{tabular}




\begin{tabular}{|c|c|c|c|c|c|}
\hline & & & \multicolumn{2}{|c|}{ GROUP } & \multirow{2}{*}{ Total } \\
\hline & & & US & BP & \\
\hline \multirow{4}{*}{ Central Line } & \multirow{2}{*}{ No } & Count & 15 & 14 & 29 \\
\hline & & $\%$ within Group & $93.8 \%$ & $87.5 \%$ & $90.6 \%$ \\
\hline & \multirow{2}{*}{ Yes } & Count & 1 & 2 & 3 \\
\hline & & \% within Group & $6.2 \%$ & $12.5 \%$ & $9.4 \%$ \\
\hline \multirow{2}{*}{\multicolumn{2}{|c|}{ Total }} & Count & 16 & 16 & 32 \\
\hline & & \% within Group & $100.0 \%$ & $100.0 \%$ & $100.0 \%$ \\
\hline
\end{tabular}

\section{DISCUSSION}

Peripheral venous access is essential to collect samples for investigations, transfuse fluids or blood and to administer drugs. Routinely, this procedure is performed by nurses; however, when access is difficult, an anaesthesiologist or emergency physician may be called. Traditional blind percutaneous approach using landmark inspection and vein palpation technique has a high success rate.[15] but a few patients may prove to be difficult to cannulate due to their medical condition, obesity, oedema, deformities, IV drug abuse, etc.

Often these patients in whom peripheral IV access is difficult are subjected to repeated attempts by multiple practitioners, delay in diagnosis and treatment or a central line placement. Such consequences involve patient discomfort and higher risk of complications in addition to being more time consuming.

Bedside ultrasonography is a convenient tool that may facilitate successful peripheral venous access faster in these patients with fewer attempts and greater patient satisfaction. A small but growing body of literature is supporting the use of ultrasound guidance for placement of peripheral lines in difficult IV access patients.[6,9,10] This study was undertaken to compare the two approaches; 32 patients included in our study were randomized into 2 groups of 16 each with 7 female and 9 male patients in both the groups (Table 1). The mean age in Group US was 54.13 and 48.94 in the Group BP. Comparison of the age between the two groups though higher in USG group with a t value of 1.081 was statistically nonsignificant [P: 0.288; Table 2].

Obesity was the most common reason for difficulty in gaining IV access $(31.9 \%)$ followed by $21.9 \%$ of the patients with the presence of oedema and hypovolemia each (Table 4). Prevalence of obesity in other studies has been reported between $29.4 \%{ }^{[8]}$ and $41.8 \% .^{[3]}$ The prevalence of obesity as a major reason for difficult intravenous access may vary from centre to centre and would affect the results in other settings.

Constantino and Colleagues.[6] did a prospective, systematically allocated study on patients with defined difficult intravenous access. They studied the success rate, time taken, number of attempts and patient satisfaction in 60 patients among whom 39 patients were cannulated using ultrasound guidance and 21 patients were subjected to traditional approach of intravenous access. Their study revealed a success rate of $97 \%$ in the ultrasonographic group compared to $33 \%$ in the other group. Also the ultrasonographic group needed lesser time since first percutaneous puncture (4 versus 15 minutes) and lesser attempts (1.7 versus 2.7) with greater patient satisfaction (8.7 versus 5.7) than the traditional landmark approach.

Other studies by Stein J.[5] and Stoltz et al[16], however, concluded that compared to traditional blind technique ultrasound guidance had no effect on time to successful cannulation or the number of attempts for successful cannulation.

In our study lesser time was needed in the US group to achieve successful cannulation (190 secs., SD 74.59 and P $<0.001$ ) when compared to the BP group, which took much longer time (435.94 secs) (Table 2). This indicates that the time spent in locating a peripheral vein was much faster using ultrasound guidance, which also aided the operator to direct the cannula achieving successful venous access once a percutaneous puncture was made.

Keyes et al[9] reported a success rate of $91 \%$, while the study by Constantino in 2003 showed 94\%.[17] We were able to achieve a successful US-guided cannulation rate of $82.3 \%$ compared to the traditional blind technique with $56.2 \%$ (Table 6). The slightly lower rate of success in our study could be the lack of previous US experience in the operator and the attempts were limited to only two instead of three in the above studies. We believe that gaining more experience by the operator would improve the success rate. Our findings are closer to those of a study by Stein et al who had a successful US-guided cannulation rate of $81 \%$ and $46 \%$ in their control group.[18]

Ultrasound guidance resulted in more successful cannulation $(62.5 \%)$ in the first attempt itself, while $37.5 \%$ of patients were cannulated in the second attempt. Blind palpation technique demonstrated the reverse. Cannulation in the BP group was less successful (31.2\%) in the first attempt, while a success of $68.8 \%$ was achieved in the second attempt (Table 5). The increased success rate is in agreement with other studies.[6,8,12,16,18]

In comparison with the BP group with low satisfaction, patients with difficult IV access who were cannulated by ultrasonographic guidance showed a higher satisfaction score. (Mean of 2.88, SD 1.025, ' $t$ ' 2.049 and 'p' 0.049) (Table 2 , Table 3). The increase in patient satisfaction of the USguided cannulation group is probably directly related to the decreased number of percutaneous punctures in that group.[6]

The BP group demonstrated more complications such as haematoma formation and arterial punctures, $45.8 \%$ and $12.5 \%$ respectively when compared to the US-guided cannulation which had no complications at all in $62.5 \%$ of cases. Haematoma was seen in $31.2 \%$ of the patients. Only one case had a complication of arterial puncture (Table 7). This is less than the complication rate noted in other studies.[9,19]

In a retrospective cohort review of 77 requests for USguided IV access, Gregg achieved near absolute success rate (99\%) with the use of US-guided IV; 34 central lines were avoided and 40 central lines were removed as a result of ultrasound-guided peripheral intravenous access being obtained.[20] Similarly, Au AK et al conducted a prospective observational study in 100 patients with inability to establish 
IV access. Ultrasound prevented the need for central venous cannula placement in $85 \%$ of these patients with difficult IV access.[21] We found that central line 'rescue' was required only in one patient (6.2\%) belonging to the US group, while 2 cases $(12.4 \%)$ needed it in the BP group. The use of ultrasonography will minimize, if not obviate the need for central line placements when initial blind attempts fail to cannulate difficult IV access patients.

\section{CONCLUSION}

The use of ultrasonography in detecting and locating otherwise hard to find veins by routine inspection and palpation is promising. Ultrasound-guided IV access offers a simple and rapidly successful modality in patients with difficult IV access.

This study concludes that IV cannulation by US guidance in patients with difficult IV access is quicker and more successful, needs less attempts and has a higher patient satisfaction together with fewer complications when compared to the traditional blind percutaneous approach. Appropriate 'hands on' training in ultrasonography should be given to all the nurses, paramedics and clinicians, so that ultrasound-guided cannulation could be included in the management protocol of patients having difficult intravenous access.

In spite of growing body of evidence on the use and advantages of US peripheral IV access, it has not gained the expected popularity among residents and physicians. This is believed to be due to the preference for central over peripheral lines in situations of difficult intravenous access as a result of perceived barriers. The barriers listed are higher procedure cost and higher skill requirement, operator dependence, increased procedural time, fear of nosocomial infections, less familiar model of US machine and question of timely availability of US machine.[20]

\section{REFERENCES}

1. Troianos CA, Hartman GS, Glas KE, et al. Special articles: guidelines for performing ultrasound-guided vascular cannulation: recommendations of the American society of echocardiography and the society of cardiovascular anesthesiologists. Anesth Analg 2012;114(1):46-72.

2. Levy JA, Noble VE. Bedside ultrasound in pediatric emergency medicine. Pediatrics 2008;121(5):e1404-12.

3. Schoenfeld E, Shokoohi H, Boniface K. Ultrasound-guided peripheral intravenous access in the emergency department: patient-centered survey. West J Emerg Med 2011;12(4):475-7.

4. Bruzoni M, Slater BJ, Wall J, et al. A prospective randomized trial of ultrasound-vs landmark-guided central venous access in the pediatric population. J Am CollSurg 2013;216(5):939-43.

5. Stein J, George B, River G, et al. Ultrasonographically guided peripheral intravenous cannulation in emergency department patients with difficult intravenous access: a randomized trial. Ann Emerg Med 2009;54(1):33-40.

6. Constantino TG, Parikh AK, Satz WA, et al. Ultrasonography-guided peripheral intravenous access versus traditional approaches in patients with difficult intravenous access. Ann Emerg Med 2005;46(5):456-61.
7. Shiver S, Blaivas M, Lyon M. A prospective comparison of ultrasound-guided and blindly placed radial artery catheters. J Academic Emergency Medicine 2006;13: 1275-9.

8. Bauman M, Braude D, Crandall C. Ultrasound-guidance vs. standard technique in difficult vascular access patients by ED technicians. Am J Emerg Med 2009;27(2): 135-40.

9. Keyes LE, Frazee BW, Snoey ER, et al. Ultrasound-guided brachial and basilica vein cannulation in emergency department patients with difficult intravenous access. Ann Emerg Med 1999;34(6):711-4.

10. Brannam L, Blaivas M, Lyon M, et al. Emergency nurses' utilization of ultrasound guidance for placement of peripheral intravenous lines in difficult access patients. Acad of Emerg Med 2004;11(12):1361-3.

11. Heinrichs J, Fritze $Z$, Vandermeer $B$, et al. Ultrasonographically guided peripheral intravenous cannulation of children and adults: a systematic review and meta-analysis. Ann Emerg Med 2013;61(4):444-54, e1.

12. Egan G, Healy D, O’Neill H, et al. Ultrasound guidance for difficult peripheral venous access: systematic review and meta-analysis. Emerg Med J 2013;30(7):521-6.

13. Doniger SJ, Ishimine P, Fox JC, et al. Randomized controlled trial of ultrasound-guided peripheral intravenous catheter placement versus traditional techniques in difficult-access pediatric patients. Pediatr Emer Care 2009;25(3):154-9.

14. Wrench JS, Thomas-Maddox C, Richmond VP, et al. Quantitative research methods for communication. $8^{\text {th }}$ ed. New York: Oxford University Press 2008:204-6.

15. Khan MS, Sabnis VB, Phansalkar DS, et al. Use of ultrasound in peripheral venous catheterization in adult emergency and critical care units. Anaesth Pain \& Intensive Care 2015;19(3):303-10.

16. Stolz LA, Stolz U, Howe C, et al. Ultrasound-guided peripheral venous access: a meta-analysis and systematic review. J Vasc Access 2015;16(4):321-6.

17. Constantino TG, Fojtik JP. Success rate of peripheral intravenous catheter insertion by emergency physicians using ultrasound guidance (abstract). Acad Emerg Med 2003;10(5):487.

18. Stein JC, Cole W, Kramer N, et al. Ultrasound-guided intravenous cannulation in emergency department patients with difficult intravenous access. Acad Emerg Med 2004;11:581-2.

19. Jones SE, Nespert TP, Alcoaloumre E. Pre-hospital intravenous line placement: a prospective study. Ann Emerg Med 1989;18(3):244-6.

20. Gregg SC, Murthi SB, Sisley AC, et al. Ultrasound-guided peripheral intravenous access in the intensive care unit. J Crit Care 2010;25(3):514-9.

21. Au AK, Rotte MJ, Grzybowski RJ, et al. Decrease in central venous catheter placement due to use of ultrasound guidance for peripheral intravenous catheters. Am J Emerg Med 2012;30(9):1950-4. 